\title{
Setting Regional Research Priorities for Sexual and Reproductive Health and Rights Services in Humanitarian Settings
}

\author{
Leopold Ouedraogo ${ }^{1 *}$, Triphonie Nkurunziza ${ }^{1}$, Assumpta Muriithi ${ }^{1}$, Chilanga Asmani ${ }^{1}$, \\ Hayfa Elamin', Bigirimana Françoise', Souleymane Zan', Gbenou Dina1, Mihretu Belete1, \\ Dadji Kwami', Kim Caron Rahn², Ali Moazzam², Tolu Lemi², Blami Dao ${ }^{3}$, Issiaka Sombie ${ }^{4}$, \\ Okech Mollent ${ }^{5}$
}

\author{
${ }^{1}$ Reproductive, Maternal Health and Ageing, WHO Regional Office for Africa, Brazzaville, Congo \\ ${ }^{2}$ Department of Reproductive Health and Research, World Health Organization, Geneva, Switzerland \\ ${ }^{3}$ JHPIEGO, Ouagadougou, Burkina Faso \\ ${ }^{4}$ West Africa Health Organization, Ouagadougou, Burkina Faso \\ ${ }^{5}$ Peak Moments Global HR Solutions, Nairobi, Kenya \\ Email: `ouedraogol@who.int, Tnkurunzizat@who.int, kimca@who.int, alimoa@who.int, muriithia@who.int, asmanic@who.int, \\ elaminha@who.int, tolul@who.int, bigirimanaf@who.int, zans@who.int, gbenoud@who.int, tafesseb@who.int, dadjik@who.int, \\ blami.dao@jhpiego.org, isombie@wahooas.org, mollentakinyi@gmail.com
}

How to cite this paper: Ouedraogo, L., Nkurunziza, T., Mureithi, A., Asmani, C., Elamin, H., Françoise, B., Zan, S., Dina, G., Belete, M., Kwami, D., Rahn, K.C., Moazzam, A., Lemi, T., Dao, B., Sombie, I. and Mollent, O. (2021) Setting Regional Research Priorities for Sexual and Reproductive Health and Rights Services in Humanitarian Settings. Advances in Reproductive Sciences, 9, 60-68.

https://doi.org/10.4236/arsci.2021.91007

Received: October 24, 2020

Accepted: December 28, 2020

Published: December 31, 2020

Copyright $\odot 2021$ by author(s) and Scientific Research Publishing Inc. This work is licensed under the Creative Commons Attribution International License (CC BY 4.0).

http://creativecommons.org/licenses/by/4.0/ (c) (i) Open Access

\begin{abstract}
Background: Despite increased recognition of the need for sexual and reproductive health and rights in humanitarian settings, evidence focusing on mainstreaming reproductive health services such as maternal, neonatal mortality, human immunodeficiency virus transmission and unsafe abortion still remains inadequate. The ability to understand the magnitude of the needs and highlight existing gaps is supported by improved data which is critical to informing effective policies, programming and funding decisions. The purpose of this report is to present the results of a research prioritization exercise on sexual and reproductive health and rights services in humanitarian settings for the WHO Africa region for the next three years. Methods: We adapted the Child Health and Nutrition Research Initiative method in three phases. Experts from the region participated in an online survey to identify key areas for research in sexual and reproductive health and rights. To identify potential areas for research, the experts ensured answerability, effectiveness, deliverability, equity and potential impact of the questions. The research areas they identified were reviewed by World Health Organization technical team from headquarters. In a meeting of 67 participants, the questions were subjected to further review and analysis. Using a modified for scoring criteria, the questions were scored and ranked to provide the top ten priority ques-
\end{abstract}


tions to address sexual and reproductive health and rights services in humanitarian settings. Results: A list of 21 priority research questions on sexual and reproductive health and rights services in humanitarian settings were scored and ranked. Top ten priorities research questions were identified. Those that scored highly by scoring 30 points out of the possible maximum of 30 include: "determining the prevalence and associated factors of unwanted pregnancies and abortions performed in emergency and humanitarian settings", "evidence on gender-based violence in humanitarian situations and its associated factors" and "defining an optimal model for coordinating sexual and reproductive health and rights interventions and responses in crisis situations". Conclusions: Top ten research priorities in sexual and reproductive health and rights services in humanitarian settings were identified. The priority research areas have the potential to identify the best areas for programming of services in humanitarian settings. It is our hope that the identified research areas will be prioritized to support programming of services in humanitarian settings based on scientific evidence.

\section{Keywords}

Humanitarian, Conflicts, Crisis, Sexual and Reproductive Health and Rights

\section{Introduction}

Recent systematic reviews have highlighted a scarcity of rigorous evidence to inform interventions in SRHR services in humanitarian settings despite the fact that global conflicts are widespread and they continue to affect many lives [1]. For this reason, specific health problems in humanitarian settings whether caused by conflict, disease outbreak or disasters need relevant, require rigorous and up-to date evidence to guide appropriate responses. Often, multiple types of crises occur simultaneously such as armed conflict or natural disasters combined with famine and disease outbreaks. Although many researchers acknowledge that conducting research in humanitarian context response can be difficult and challenging, however, more research is still needed to provide evidence for improved solutions [2].

According to WHO, providing comprehensive SRHR services in humanitarian settings can yield important health and social benefits for vulnerable populations. The universal health coverage framework focuses attention primarily on comprehensive sexual and reproductive health and rights services for the most vulnerable communities including those in humanitarian settings [3]. It is estimated that about 135.7 million people around the world have been affected with women and girls of reproductive age bearing the heaviest burden [4]. Globally, preventable deaths from diseases with risks factors point towards SRHR [5]. These crises have long-term health eventualities on many people affected by such crises especially in low and middle-income countries (LMIC), yet the evidence base that informs THE response in humanitarian settings is weak [6].

According to $\mathrm{WHO}$, humanitarian emergencies often have a disproportionate 
effect on the poorest and most vulnerable, particularly women, adolescents and children. There is often lack of SRHR services including family planning, saving lives in obstetric complications and even preventing diseases [7] [8]. Maternal and neonatal mortality is high in the areas affected by emergencies. Universal access to health that integrates comprehensive SRHR services is critical to reduce related morbidity and mortality.

Due to the varied nature of conflicts and other related crises that cause human suffering, deficiency of evidence is common. It is therefore imperative that evidence based research priorities are identified to ensure appropriate interventions are provided [9] [10]. Additionally, humanitarian responses cannot be expected to achieve optimal health outcomes without a rigorous and scientific evidence base [11] [12]. Prioritizing health research in these settings is often very difficult and currently there is a limited amount of scientific evidence that can inform effective humanitarian responses to guide governments, development agencies and humanitarian organizations.

There is a justification to conduct priority research that can inform relevant responses to policies, programs and interventions amongst other health challenges and their outcomes. Research prioritization is a prime mechanism for evidence-based policies and interventions towards better global health. It is against this background that the WHO African Region undertook an exercise to identify research priorities in SRHR services in humanitarian settings to guide the research agenda for the next three years and also to guide countries to improve their ability to respond to the circumstances. Such priorities would serve to elucidate key areas of research focus.

\section{Methods}

This paper reports part of a larger research prioritization exercise conducted by the WHO African region. The paper focuses on sexual and reproductive health and rights services in humanitarian settings. The research prioritization exercise adopted the Child Health and Nutrition Research Initiative (CHNRI). A consultative and consensus based approach with experts in SRHR taking into consideration their voices produced the first potential areas for debate. In considering the questions for discussion, the experts were guided by the following qualities; answerability, effectiveness, deliverability, equity and potential impact of the areas. The implementation was process took three phases. 1) Generation and collection of researchable questions online using experts 2) review, consolidation and thematic analysis of the potential research by WHO HQ experts and 3) scoring and ranking of the questions to identify priority questions using pre-defined scoring criteria.

In the first phase, an online questionnaire was administered in August 2019 to SRHR experts in various countries across the region to collect potential areas of research in sexual and reproductive health and rights. The countries included Benin, Burkina Faso, Chad, DRC Congo, Ethiopia, Rwanda, South Africa, Gha- 
na, Kenya, Nigeria, Mali, Guinea and Central Africa Republic. The online suggestions were received by a technical team of WHO HQs in September 2019 for review and consolidation. The online survey built on the results from a prior research prioritization exercise conducted by EMRO and AFRO in 2016 [13].

Both the second and third phases of the research prioritization process were conducted in a meeting held in Cape Town, South Africa from $29^{\text {th }}$ October to $1^{\text {st }}$ November, 2019. A total of 67 participants from the 80 who were invited attended. The experts worked in 12 groups to work on the questions that were organized into 12 thematic areas. The group work entailed reviewing the questions to remove the questions that were out of scope and those that appeared to have duplications were merged. A total of 21 research priority questions on sexual and reproductive health and rights services in humanitarian settings were proposed for level three.

During the third phase of the research prioritization process, four experts analyzed the 21 questions from phase 2. Using the scoring criteria in Table 1, the questions were scored and ranked. The scoring criteria had 1 as the lowest score and 5 as the highest score. Each question could therefore attain a lowest score of 6 or highest score of 30 .

\section{Results}

The aim of the exercise was to identify priority research questions on SRHR services in humanitarian settings. In this paper, we report a part of the results of a research prioritization exercise focusing on sexual and reproductive health and rights services in humanitarian settings. 67 experts participated in the meeting thereby eliciting a response rate of 83.7 percent.

The scores ranged from 30 to 25 points for the top ten priority questions. Table 2

Table 1. Scoring criteria.

\begin{tabular}{|c|c|c|}
\hline Criteria & Definition & Scoring \\
\hline 1) Magnitude & $\begin{array}{l}\text { Magnitude of the problem; in terms of the proportion of the population, such as women, under } 5 \\
\text { children, elderly, are affected. }\end{array}$ & $1-2-3-4-5$ \\
\hline 2) Severity & $\begin{array}{l}\text { Of the condition; i.e. danger to the individual and the community. How serious is the condition. Does it } \\
\text { threaten life, cause major suffering, and decrease the ability to lead a normal life. }\end{array}$ & $1-2-3-4-5$ \\
\hline 3) Effectiveness & $\begin{array}{l}\text { Based on the best existing evidence and knowledge, would intervention be efficacious in reducing disease } \\
\text { burden? It is likely to be effective under programme conditions. }\end{array}$ & $1-2-3-4-5$ \\
\hline 4) Feasibility & $\begin{array}{l}\text { Taking into account a) the infrastructure and resources required to deliver effective interventions (e.g. } \\
\text { human resources, health facilities, communication and transport infrastructure), and b) the need for } \\
\text { change in demand, beliefs and attitudes of users, would you say that the endpoints of the research would } \\
\text { be deliverable? Affordability and sustainability. }\end{array}$ & $1-2-3-4-5$ \\
\hline 5) Burden & $\begin{array}{l}\text { Diseases burden reduction; taking into account the best available information, would you say that } \\
\text { reaching of research endpoints would eventually, have a "capacity" to impact directly and indirectly } \\
\text { disease burden. E.g. up to } 5 \% \text { to } 10 \% \text { reduction in long run. }\end{array}$ & $1-2-3-4-5$ \\
\hline 6) Equity & $\begin{array}{l}\text { Equity enhancing; does the intervention affect mainly the underprivileged in the population? } \\
\text { Intervention has potential to improve equity in disease burden distribution in the longer term? }\end{array}$ & $1-2-3-4-5$ \\
\hline
\end{tabular}

1 is the lowest score and 5 the highest score. Each question could therefore attain a lowest score of 6 or highest score of 30 . 
Table 2. Top ten research priority questions on SRHR services in humanitarian settings.

\begin{tabular}{|c|c|c|c|c|c|c|c|}
\hline Title of the research questions & Magnitude & e Severity & Effectiveness & Feasibility & Burden & Equity & $\begin{array}{l}\text { Total } \\
\text { scores }\end{array}$ \\
\hline $\begin{array}{l}\text { 1) Determine the prevalence and associated factors of } \\
\text { unwanted pregnancies and abortions performed under } \\
\text { conditions of humanitarian emergency. }\end{array}$ & 5 & 5 & 5 & 5 & 5 & 5 & 30 \\
\hline $\begin{array}{l}\text { 2) Evidence on gender-based violence in humanitarian } \\
\text { situations and associated factors. }\end{array}$ & 5 & 5 & 5 & 5 & 5 & 5 & 30 \\
\hline $\begin{array}{l}\text { 3) Define an optimal model for coordinating SRH } \\
\text { interventions and responders in crisis situations. }\end{array}$ & 5 & 5 & 5 & 5 & 5 & 5 & 30 \\
\hline $\begin{array}{l}\text { 4) Assess the scope and operational capacities of psychosocial } \\
\text { services in humanitarian situations. }\end{array}$ & 4 & 5 & 4 & 5 & 5 & 5 & 28 \\
\hline $\begin{array}{l}\text { 5) Evaluate the effectiveness of strategies implemented to } \\
\text { improve access to information and the provision of SRH } \\
\text { services for adolescents in humanitarian situations? }\end{array}$ & 5 & 4 & 4 & 4 & 5 & 5 & 27 \\
\hline $\begin{array}{l}\text { 6) Assess the availability of SRHR services required in } \\
\text { humanitarian situations under the six pillars of the health } \\
\text { system. }\end{array}$ & 5 & 4 & 4 & 5 & 4 & 5 & 27 \\
\hline $\begin{array}{l}\text { 7) Assess providers' SRH knowledge and practices in all phases } \\
\text { of crisis in a humanitarian emergency. }\end{array}$ & 5 & 5 & 4 & 4 & 4 & 5 & 27 \\
\hline $\begin{array}{l}\text { 8) Assess public satisfaction with SRHR services in } \\
\text { humanitarian situations. }\end{array}$ & 5 & 4 & 3 & 5 & 4 & 5 & 26 \\
\hline $\begin{array}{l}\text { 9) Factors associated with improving the acceptability and } \\
\text { accessibility of LARC for women of childbearing age in } \\
\text { humanitarian situations? }\end{array}$ & 5 & 4 & 3 & 4 & 4 & 5 & 25 \\
\hline $\begin{array}{l}\text { 10) Extent, types and complications of non-communicable } \\
\text { diseases in pregnant women in humanitarian situations }\end{array}$ & 3 & 4 & 4 & 4 & 5 & 5 & 25 \\
\hline
\end{tabular}

presents the distribution of the results as ranked. The top three questions include; "determine the prevalence and associated factors of unwanted pregnancies and abortions performed under conditions of humanitarian emergency"; "evidence on gender-based violence in humanitarian situations and associated factors"; and "defining an optimal model for coordinating SRHR interventions and responders in crisis situations". The other research question that was ranked high at 28 was "assessment of the scope and operational capacities of psychosocial services in humanitarian situations". The question that received the lowest score of 25 points out of the ten was on "the extent, types and complications of non-communicable diseases in pregnant women in humanitarian situations". The priorities identified should support decisions as humanitarian action relies on a broad range of evidence ranging from quantitative data from surveys, from experts inputs as well as from routine programme monitoring.

\section{Discussion}

A 2015 study from three crisis-affected settings in sub-Saharan Africa found that only five of 63 assessed health facilities provided adequate emergency obstetric 
and newborn care, and only three provided elements of clinical management of rape [14]. Safe abortion was unavailable across settings, despite unsafe abortion having been estimated to cause $25 \%$ - $50 \%$ of maternal deaths in refugee settings [15]. Certain groups, such as adolescents and older women, male survivors of sexual violence, sex workers, people living with disabilities or those of diverse sexual orientations and gender identity and/or expression continue to face significant obstacles in accessing information and services in humanitarian settings [16] [17].

Major challenges in conducting rigorous research in SRHR services in humanitarian settings is because most of the research is done by persons involved in delivering aid thus research takes the second place after providing lifesaving. Deficient health systems, shortages of skilled health providers, supply stock-outs, and restrictive policy environments hinder effective SRHR service provision in crisis situations. Humanitarian crises expose weaknesses in health systems, with particularly serious consequences for women, young people and marginalized groups. Often, these challenges were present before the crisis and are further exacerbated by the humanitarian situation. Socio-economic and cultural barriers, gender inequality and a lack of information about the availability and benefits of care also impede service uptake [18]. Addressing these challenges requires harmonization of efforts and improved organizational policies, but most importantly sufficient funding and adequate capacity.

Integration of sexual and reproductive health and rights into humanitarian and fragile settings responses has grown globally. The awareness of the consequences of neglecting reproductive health services, such as maternal and neonatal mortality, HIV transmission, and unsafe abortion, has expanded [19]. Since the 1990's recognition of SRHR needs for crisis affected persons has grown slowly in the international community starting with the development of the UNHCR guidelines on protection of refugee women [20] and to date a global action declaring access to comprehensive SRHR is a basic human right. Our research prioritization exercise recommends that research for SRHR services in humanitarians settings respond to these recognized priorities. This is because humanitarian needs are varied and the only way to take action on the people affected differently by the crises requires relevant knowledge that is contextualized to respond appropriately.

\section{Conclusion}

Priority research areas in sexual and reproductive health and rights services in humanitarian settings were identified. Rigorous, scientific research that assesses the scope of SRHR services in humanitarian settings, examines cost effectiveness, beneficial public health interventions and translates evidence to practice is critical to the WHO Africa region.

\section{Authors Contribution}

NT, OL, BF, MS, DK, DS, AC and EH conceptualized the exercise. KC, AM, TL 
provided technical support. All authors read and approved the final manuscript.

\section{Acknowledgements}

We thank all the experts who were involved in the research prioritization exercise for WHO Africa Region. They include: Zan Souleymane, Moufalilou Aboubakar, Bokossa Alexis Richard, Gaston D. Ahounou, Dina Gbenou, Hien Clotaire, Kiemtoré Sibraogo, Traoré Isidore Tiandiogo, Bassounda, Poïdigem, Dadjoari Moussa, Nguetabe Odile, Awad Adam Awad, Foumsou, Kini Brigitte Nsiku, Haimanot Ambelu Workineh, Tenaye Kebede, Girma Gemechu, Mekdes Daba, Deo Roseline, Samuel Oppong, Ivy Osei, Patrick K. Aboagye, Sy Telly, Férida Mara, Alpha Ahmadou Diallo, Tessougue Fatoumata, Idrissa Cissé, Sidy Diallo, Ben Moulaye Haidara, Moussa Kamissoko, Ojo Olumuyiwa, Ufere Joy, Ikpeze Okechukwu Christian, Chris Ega, Kabuteni Theopista John, Utumatwishima Jean Nepo, Ndaruhutse Victor, Ruzindana Kenneth, Mihretu Belete, Sithembile Dlamini-Nqeketo, K.S. Dithole, Rapinyana O., Ntombi Mtshali, Mercy Pindani, Azwihangwisi Helen Mavhandu-Mudzusi, Uta Lehmann, Boniface Ushie, David Norris, Blami Dao, Issiaka Sombie, Seni Kouanda, Richard Adanu, Goma Mboungou Mierette, Mavounia Ndoko Genil, Ngwenya, Mmamoitlamo and Mncwabe Pearl.

\section{Funding}

The WHO Regional office for Africa.

\section{Conflicts of Interest}

All authors declare no competing interests.

\section{References}

[1] World Health Assembly, 63 (2010) WHO's Role and Responsibilities in Health Research.

[2] Leresche, E., Truppa, C., Martin, C., et al. (2020) Conducting Operational Research in Humanitarian Settings: Is There a Shared Path for Humanitarians, National Public Health Authorities and Academics? Conflict and Health, 14, Article No. 25. https://doi.org/10.1186/s13031-020-00280-2

[3] Universal Health Coverage (UHC) in Africa: A Framework for Action: Main Report. World Bank, Washington DC. http://documents.worldbank.org/curated/en/735071472096342073/

[4] World Health Organization (2017) Inter-Agency Field Manual on Reproductive Health in Humanitarian Settings. http://docs.unocha.org/sites/dms

[5] United Nations Office for the Coordination of Humanitarian Affairs (UNOCHA). (2019) Global Humanitarian Overview 2019. United Nations, Geneva.

[6] United Nations Population Fund (UNFPA) (2015) The State of World Population 2015: Shelter from the Storm. UNFPA, New York.

[7] United Nations Office for the Coordination of Humanitarian Affairs (OCHA) (2017) Global Humanitarian Overview. OCHA, New York. 
[8] United Nations Population Fund (UNFPA) (2015) The State of World Population 2015: Shelter from the Storm. UNFPA, New York. http://www.unfpa.org/swop-2015

[9] World Health Organization (WHO) (2018) WHO Fact Sheets, 2018. https://www.who.int/news-room/fact-sheets/detail/adolescent-mental-health

[10] United Nations Population Fund (UNFPA). Humanitarian Action Overview 2019. https://www.unfpa.org/humanitarian-action-2019-overview

[11] United Nations High Commissioner for Refugees (UNHCR) (2018) Global Trends: Forced Displacement in 2017. United Nations, Geneva.

[12] IASC (2014) Inter-Agency Standing Committee (IASC) Reference Group for Mental Health and Psychosocial Support in Emergency Settings. Recommendations for Conducting Ethical Mental Health and Psychosocial Research in Emergency Settings.

[13] United Nations Office for the Coordination of Humanitarian Affairs (UNOCHA) (2018) World Humanitarian Data and Trends 2018. United Nations, Geneva.

[14] Desrosiers, A., Betancourt, T., Kergoat, Y., Servilli, C., Say, L. and Kobeissi, L. (2020) A Systematic Review of Sexual and Reproductive Health Interventions for Young People in Humanitarian and Lower-and-Middle-Income Country Settings. BMC Public Health, 20, Article No. 666.

https://doi.org/10.1186/s12889-020-08818-y

[15] Rudan, I., Chopra, M., Kapiriri, L., Gibson, J., Lansang, M.A., et al. (2008) Setting Priorities in Global Child Health Research Investments: Universal Challenges and Conceptual Framework. Croatian Medical Journal, 49, 398-408. https://doi.org/10.3325/cmj.2008.3.307

[16] Ali, M., Farron, M., Quedraogo, L., Mahaini, R.K., Miller, K. and Kabra, R. (2018) Research Gaps and Emerging Priorities in Sexual and Reproductive Health in Africa and Eastern Mediterranean Regions. Reproductive Health Journal, 15, Article No. 39. https://doi.org/10.1186/s12978-018-0484-9

[17] Mendis, S. and Alwan, A., Eds. (2011) Prioritized Research Agenda for Prevention and Control of Noncommunicable Diseases. World Health Organization, Geneva.

[18] Souza, J.P., Widmer, M., Gülmezoglu, A.M., Lawrie, T.A., Adejuyigbe, E.A., Carroli, G., Crowther, C., Currie, S.M., Dowswell, T., Hofmeyr, J., et al. (2014) Maternal and Perinatal Health Research Priorities beyond 2015: An International Survey and Prioritization Exercise. Reproductive Health, 11, Article No. 61. https://doi.org/10.1186/1742-4755-11-61

[19] Reis, C., Ed. (2015) Taking Stock of Reproductive Health in Humanitarian Settings: 2012-2014 Inter-Agency Working Group on Reproductive Health in Crises' Global Review. Conflict and Health, 9, Suppl 1.

[20] Chaudhary, P., Vallese, G., Thapa, M., et al. (2017) Humanitarian Response to Reproductive and Sexual Health Needs in a Disaster: The Nepal Earthquake 2015 Case Study. Reproductive Health Matters, 25, 25-39.

https://doi.org/10.1080/09688080.2017.1405664 


\section{Abbreviations}

CHNRI: Child health and nutrition research initiatives; WHO: World Health Organization; UHC: Universal health coverage; SRHR: sexual and reproductive health and rights. 